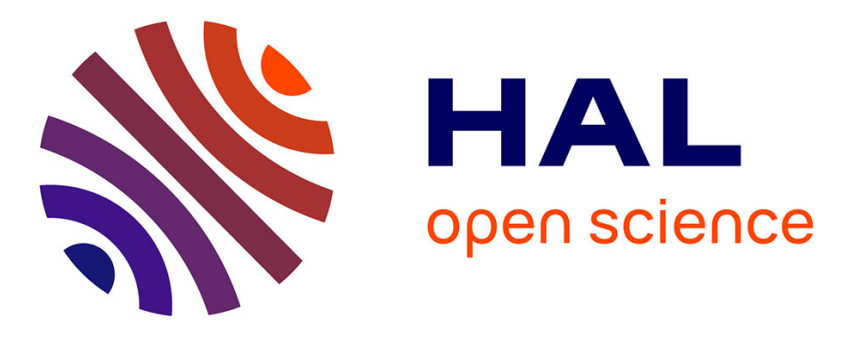

\title{
Using just-in-time information to support scientific discovery learning about geometrical optics in a computer-based simulation
}

Casper Hulshof, Ton de Jong

\section{- To cite this version:}

Casper Hulshof, Ton de Jong. Using just-in-time information to support scientific discovery learning about geometrical optics in a computer-based simulation. Interactive Learning Environments, 2006, 14 (1), pp.79-94. 10.1080/10494820600769171 . hal-00190688

\section{HAL Id: hal-00190688 \\ https://telearn.archives-ouvertes.fr/hal-00190688}

Submitted on 23 Nov 2007

HAL is a multi-disciplinary open access archive for the deposit and dissemination of scientific research documents, whether they are published or not. The documents may come from teaching and research institutions in France or abroad, or from public or private research centers.
L'archive ouverte pluridisciplinaire HAL, est destinée au dépôt et à la diffusion de documents scientifiques de niveau recherche, publiés ou non, émanant des établissements d'enseignement et de recherche français ou étrangers, des laboratoires publics ou privés. 
This is an electronic version of the article published in: Hulshof, C. D., \& de Jong, T. (2006). Using just-in-time information to support scientific discovery learning about geometrical optics in a computer-based simulation. Interactive Learning Environments, 14 (1), 79-94 (C) 2006 Taylor \& Francis. Interactive Learning Environments is available online at: http://www.informaworld.com/openurl?genre=article\&issn=1049$\underline{4820 \& \text { volume }=14 \& \text { issue }=1 \& \text { spage }=79}$

\title{
Using just-in-time information to support discovery learning about geometrical optics in a computer-based simulation
}

\author{
C. D. Hulshof ${ }^{*} \&$ T. de Jong \\ Faculty of Behavioural Sciences, Department of Instructional Technology, University of Twente, PO Box 217, \\ 7500 AE, Enschede, The Netherlands
}

\begin{abstract}
Many problems that learners regularly encounter during discovery learning with computer-based simulations have been identified. A number of studies have examined different ways of support for discovery learning by facilitating the learning process. This study examines the effect of facilitating access to prior knowledge through just-in-time information. It is expected that access to just-in-time information will foster learning but will not interfere with it. To test these hypotheses, an experiment was conducted in which a group of students who worked with a computer simulation had access during learning to 'knowledge tips'. Performance of this group was compared with that of a group who had no access to knowledge tips. It was found that the experiment group showed a better learning gain than the control group. The implications of the results are shortly discussed.
\end{abstract}

\section{Introduction}

While computers continue to advance into virtually all aspects of our culture, their effective use in education is still surrounded by controversy (Stoll, 1999). Although considerable progress has been made in understanding of the opportunities and potential that computers offer for educational practice, some aspects remain problematic. A review by Angrist and Lavy (2002) of the Israeli Tomorrow-98 programme, a billion-dollar venture aimed at creating an environment supportive of integrating information technologies in the classroom, has shown very little beneficial short-term effects of increased computer use. This has led the authors to conclude that 'money spent on CAI [Computer Aided Instruction] in Israel would have been better spent on other inputs (p. 761)'. These findings show that, viewed on a large scale, there exist many factors that impede successful implementation of computers in educational situations. On a smaller scale, much research has been devoted to studying the specific circumstances under which computers can be effective learning tools. This is usually done by comparing various types of computer-based instruction to more traditional forms of learning. One type of instruction that fully exploits the potential of computer-regulated learning is known as discovery learning (De Jong \& Van Joolingen, 1998). Discovery learning means that the content of a domain is not explicitly stated to learners. Instead, learners have to 'discover' the material for themselves using techniques that can be compared

\footnotetext{
* Corresponding author. Tel.: +31-53-4893562/4894359; fax: +31-53-4892895.

E-mail address: c.d.hulshof@utwente.nl
} 
to the behavior of a scientist who explores a domain. A technique that has proven useful in eliciting discovery learning processes is by the use of computer simulations (De Jong, 1991; De Jong \& Van Joolingen, 1998). A computer simulation provides students with a virtual environment in which they can design and perform different types of experiments, and observe the effect of manipulating variables in various ways. When used as an instructional tool, students' task is to induce the relations between variables in the simulated domain through exploration, experimenting, and discovery. A central characteristic of discovery learning is that information is not delivered to students in a piecemeal fashion. Instead, the process is a relatively demanding one: students are required to gather evidence themselves and accordingly construct, shape, and modify personal hypotheses. It is supposed that during learning, through various 'acts of discovery', experimental evidence is transformed in such a way that new information can be induced (Bruner, 1961). The complete process of experimenting and inducing rules should gradually lead to understanding of the model that underlies behavior of the simulated system. In an information-processing description of the discovery learning process, two main cognitive processes can be distinguished: transformative and regulative processes (Njoo \& De Jong, 1993). Transformative processes include all the reasoning and decision making that guide manipulating a computer simulation and extracting information from it. These involve orientation, hypothesis generation, hypothesis testing, and drawing conclusions. The goal of transformative processes is to produce new information. Regulative processes are meant to control the discovery learning process on a metacognitive level. This involves monitoring one's own behavior, keeping track of progress, and planning in advance what steps to undertake.

Since discovery learning involves so many different processes that need to occur simultaneously on different levels of cognition, it is perhaps not surprising that it has been difficult to prove its effectiveness. The problems that students encounter in discovery learning can be classified into four components: hypothesis generation, design of experiments, interpretation of data, and regulation of learning (De Jong \& Van Joolingen, 1998). Proper performance of all the component tasks that make up the learning process requires both (partial) knowledge, and skills necessary to execute and complete each task. Research on discovery learning has identified at least four factors that influence the learning process, and determine its effectiveness: prior domain-specific knowledge, generic knowledge of quantitative and qualitative relations between variables, discovery skill, and metacognition (De Jong, Beishuizen, Hulshof, Prins, van Rijn, van Someren, Veenman \& Wilhelm, in press). Domain-specific knowledge and generic (domain-general) knowledge are partially independent entities. Discovery skill refers to a specfic ability, ie. student's aptitude for performing and interpreting experiments. Metacognition refers to the generic ability to regulate discovery learning processes. Knowledge and skills contribute differently to the process of transformation and regulation. Here, a short description is given of the way knowledge and skill influence discovery learning.

Knowledge plays an important role in determining the steps that learners undertake in the process of experimenting with a simulation and discovering information. Even transformative processes that yield knowledge themselves require at least some prior knowledge to function. For example, lack of prior domain-specific knowledge makes the process of orientation difficult, since learners who lack knowledge will have trouble separating relevant from irrelevant variables, which will cause them to overlook potentially interesting relations between variables (Veermans, 2001). The determining role that prior knowledge plays in setting up a context for discovery learning is reflected in the SDDS framework (Scientific 
Discovery as Dual-space Search) by Klahr and Dunbar (1988). Klahr \& Dunbar likened the process of discovery of a rule (that is, discovery of the relation between an input and output variable) to problem solving. SDDS extends the problem solving model by Newell and Simon (1972), which describes it as a search through a problem space. In SDDS, two ('dual') search spaces are postulated: hypothesis space and experiment space. In this view, the process of discovery entails traversing both search spaces, so that the end result is a set of rules that correctly describe the observed behavior of variables. During learning, searching each of the problem spaces requires different decisions. Van Joolingen \& De Jong (1997) have given an overview of the decisions that guide the search through the two spaces. For example, in experiment space search is guided by the choice of variables to manipulate and the values to assign to these. In hypothesis space, search is guided by manipulations that operate on one of more of the set of hypotheses a learner has in mind (e.g., change a hypothesis about a qualitative relation between two variables into a quantitative). When behavior during rule discovery is studied, a a broad distinction can be observed between students who follow a hypothesis-oriented approach and students who follow an experimentoriented approach. Students can be broadly classified as being either 'theorists' or 'experimenters', based on the manner in which they discover a rule. Klahr has stated that the distinction between an experimenter and theorist approach to rule discovery stems from differences in prior knowledge (Klahr, 2000, p. 77). From this description it becomes clear that knowledge not only should help students in making sense of a learning situation, but should also influence the discovery learning process itself. Although the claim that prior knowledge affects rule discovery to a large extent is supported by empirical data, it is uncertain if this notion can be extrapolated to include discovery learning in the type of complex learning environment that a computer simulation entails. In previous studies that we conducted (Hulshof, 2001; Hulshof \& De Jong, 2004), only limited effects of prior knowledge on discovery learning were found. Moreover, it was found that prior domainspecific knowledge about the simulated domain (geometrical optics) was poor in general. Learning results showed that students did not improve from pretest to posttest, and even tended to get worse. The implication of these findings is that discovery learning with a computer simulation can be severely hampered by students' lack of prior knowledge.

In addition to knowledge, students' level of discovery skills is assumed to influence the type of experiments a student performs in a simulation, especially the sequence in which experiments are performed. For discovery learning to be successful, experiments should be performed in such a way that enough cognitive resources needed to make inferences from observation of the experiment data are available. However, many students show shortcomings in their approach to experimenting. As Tschirgi (1980) has observed, students tend to change more than one variable from experiment to experiment, which in most cases is a suboptimal strategy. In a study by Klahr \& Nigam (2004), the effect of direct instruction on learning about the 'control of variables strategy' (CVS; also known as the VOTAT-strategy, cf. Tschirgi, 1980) was compared with that of discovery learning about the strategy. The results were in favor of direct instruction: not only did more children in the 'direct instruction' condition learn about the strategy, they also were better able to make better scientific judgements. As Klahr and Nibam point out, the main difference between direct instruction and discovery learning in their experiment lay in the information and feedback that was given to students: whereas students in the direct instruction condition received ample feedback and information, students in the discovery learning condition were shown no examples or given any explanations. 
Given the findings that many students appear to lack the knowledge and skills that are required for successful discovery learning, the implication seems to be clear: discovery learning can not be as effective as direct instruction because many students lack either or both the knowledge or the skills necessary to guide transformative and regulative learning processes. However, there are a number of ways in which the situation can be remedied.

Students can be supported during discovery learning in various ways. Regulative processes can be supported by structuring a computer simulation, for example by starting with a simple simulation and gradually moving on to more complex situations. Transformative processes (Orientation, hypothesis generation and testing, and drawing conclusions) can be fostered by adding 'support tools' to a computer simulation. However, support is not always effective. It can even have the effect of degrading, or hampering, performance (Pieters \& Van der Meij, 1994). For example, Van Joolingen (1993) used a structured hypothesis scratchpad to help students in making hypotheses explicit. It was expected that students who had this scratchpad at their disposal would come up with more and better hypotheses than students who did not. The actual result was that students who had the hypothesis scratchpad available conducted fewer experiments and stated fewer hypotheses than students who did not. Addition of a hypothesis scratchpad to a computer simulation did not help students in conducting experiments and generating hypotheses. The problem may have been that the addition of a tool to an already complex learning situation provided an extra task to learners, which they found difficult to cope with given the relatively short time for the experiment. Shute (1993) has argued that tools that aim at supporting discovery learning can interfere with the learning process itself. This interference disrupts compilation of knowledge and can have an adverse effect on learning. Although support tools may help in the process of hypothesis testing, they do not provide the information that is needed for orientation. Shute (1993) found that the availability of an on-line hypertext containing definitions and explanations had a positive effect on discovery learning. Leutner (1993) emphasizes that providing information to students should be carefully timed, since providing it before a learning session does not seem to help students in making sense of a learning situation. Berry and Broadbent (1987) argue that the effect of providing information is much higher if it is made available to students as soon as they need it, on a 'just-in-time'-base. A potential problem in offering support in the form of tools or on-line information is that it may influence the discovery learning process. This may detract from the potential advantages that this type of learning has over direct instruction. Therefore, to preserve the characteristics of discover learning, support should have minimal influences on the learning process itself. Students should be free to explore a simulation environment, and to design their own experiments.

Based on the discussion above, it was hypothesized that an effective type of support for discovery learning, which does not disrupt the learning process, should conform to the following three principles: support should be 1) unobtrusive, 2) minimal, and 3) available on a just-in-time base. The support should be unobtrusive in the sense that it should not be necessary for all students to use the support as part of the learning process. The optimal situation is one in which students should be able to get by with a minimum access to the support measure. Support should be minimal because otherwise it will interfere with the learning process, which may have detrimental effects. Also, support is meant to scaffold the discovery learning of students, not replace it. Finally, support should be available at the moment that students require it. This means that support should not be provided too early (in which case students may be confused by it) or too late (in which case the support has lost its relevancy). 
The question that the present research attempts to answer is twofold. First, is it possible to provide the type of just-in-time support to students in the context of discovery learning with a computer simulation? Secondly, is such support effective, compared to a situation in which it is not available? To answer these questions, a special type of 'knowledge tips' support was created. This support consisted of a number of short blocks of text that contained domainspecific and general information. An attempts was made to deliver these information blocks in such a way so that they were available to students on a just-in-time base. The support was made to be unobtrusive in the sense that students were not required to access the information at any time during learning. The information blocks were minimal in the sense that the information that was given was short and succinct. The context in which the support measure was evaluated was a computer simulation (called 'Optics') on the topic of geometrical optics. The simulation was set up in such a way that there was a lot of room for exploration of the relations underlying the behavior of light through a lens.

It is expected that access to knowledge tips fosters discovery learning with the Optics simulation. Students who can access knowledge tips during learning should show a higher learning gain than students who work freely with a computer simulation. Further, it is expected that if the support measure succeeds in being unobtrusive, it should not interfere too much with the learning process itself. Therefore, only minimal differences between students who use knowledge tips and students who do not are expected with respect to interaction behavior with a computer simulation. Finally, it is expected that there will be variation in the number of tips that students access. Students with poor domain-specific prior knowledge are expected to make less use of knowledge tips than students with high domain-specific knowledge. This expectation is in accordance with a finding by Hasselerharm and Leemkuil (1990), who found that students with little prior domain-specific knowledge made less use of an optional support tool than students with high ability.

\section{Method}

\section{Participants}

Thirty-two subjects participated in the experiment. All subjects were students who were following technical vocational education, The mean age of the subjects was 19 years. Subjects came from two school classes, both in the same year of study. All had followed a physics course as part of the curriculum. Subjects received a financial compensation of $€ 23$ for their participation in both experimental sessions.

\section{Design}

A two-group pre-posttest design was used for the experiment. Two conditions were used, an experiment condition and a control condition. Subjects were randomly assigned to one condition. Computers were positioned in such a way that subjects in different conditions were not seated next to each other. In both conditions, subjects worked with the Optics simulation environment. In the experiment condition, subjects were informed about the ability to access so-called 'knowledge tips'. In the control condition, subjects did not have access to these tips. 


\section{Learning environment}

The learning environment that was used in the experiment was the Optics computer simulation (De Jong et al., in press). The simulated domain was basic geometrical optics. The simulation allowed subjects to experiment with a virtual optical workbench, in which the properties of light and different kinds of lenses could be explored. In Figure 1, an example of the simulation is shown.

Figure 1 about here

The figure shows a complex, but not untypical, situation that subject could create. The simulation can be divided into two areas. At the top, a row of icons indicates the operations subjects could select to perform in the simulation. The bottom part, called the 'working area', is where subjects could manipulate objects, such as different types of lamps and lenses. In the figure, a large lamp on the left is sending light in all directions. Light passes through a surface filled with holes. Together, the holes form an L-shape. Divergent light rays that originate from the holes in the surface pass through a lens (marked ' $\mathrm{C}$ '). Because the surface is within the focal length of the lens, no image is projected on the screen at the right. Instead, a virtual image is formed. This virtual image can be made visible by the use of the 'eye'-tool (positioned at the right). The virtual image is marked by a blue circle. It was possible to measure properties of the virtual image, as if it were a normal projected image. In the figure, the top row shows on the left three different lenses that were available to experiment with (the lenses had different focal distances). Next to the large lamp (which is positioned on the left of the working area, and can not be moved), a lamp with one light beam, a lamp with three divergent light beams, and a lamp with three parallel light beams were available. Both horizontal and vertical distances could be measured, and also the angle with which a light beam entered or exited the lens. Light beams could also be rotated a specific number of degrees. As an extra aid, light beams could be extended in any direction by adding one or more help lines. Subjects were allowed to make notes while they worked with the simulation. For this they were handed paper; there was no need to enter notes in the simulation itself.

\section{Knowledge tips}

In the experiment condition, nine knowledge tips were available to subjects. Figure 2 shows two examples of tips that were used in the experiment.

Figure 2 about here 
As can be seen from the table, tips could consist of multiple parts. The first part of each tip contained domain-specific information on some concept of geometrical optics. The second part contained general advice on how experiments could be used in the Optics simulation to observe the information given in the first part. Also, relevant objects that could be used to perform appropriate experiments were listed. Finally, some tips gave a clue about the expected outcome of experiments. Knowledge tips could be accessed at any time by subjects, but they were not required to access any. In the experiment condition, the bottom line of the Optics simulation contained a set of nine small icons, one for each tip. Clicking on an icon would open a small popup-window in the simulation. Tips were not accessible immediately. Instead, new tips were made available every three minutes. The first tip was available after three minutes, the second after six, and so on until the last tip. After 27 minutes, all nine tips were available. When a tip became available, its corresponding icon changed color; it could then be accessed. Once a tip had become available, it could be accessed and closed as many times as subjects preferred.

Tests

Three pretests were administered: a test for domain-specific knowledge about geometrical optics, a test for generic knowledge about mathematical relations, and a test for experimentation skills in the context of a discovery task. At the end of the experiment, a domain-specific knowledge posttest was administered.

Two example items from the generic knowledge test about mathematical relations are shown in Figure 3. The test was a paper-and-pencil test, consisting of 32 items in total. Of these, 29 were multiple-choice items. The other items required a short written explanation, such as a formula.

Figure 3 about here

The test for domain-specific knowledge about geometrical optics was a paper-and-pencil multiple-choice test consisting of 30 items in total. Two example items are shown in Figure 4. The test contained items that asked for conceptual knowledge about geometrical optics, and items that required subjects to predict how changes in a situation would affect light propagation through a lens. In the test, pictures that represented situations similar to those in the Optics simulation were used to present situations about which multiple questions were asked.

Figure 4 about here 
The test for discovery skills used a combination of a computer task and a paper-and-pencil test. The computer task was an adapted version of the FILE task (described in detail in Hulshof, Wilhelm, Beishuizen \& van Rijn, 2004; also see Wilhelm, Beishuizen \& van Rijn, 2004). The maximum time subjects were allowed to work with the computer task was 30 minutes. After subjects had indicated that they knew the effect of the five variables in the FILE task, a paper-and-pencil test was administered, which consisted of 6 short questions. Test items required subjects to state the effect of each of the five variables in the FILE task on the outcome. Based on the answers, subjects were classified in one of 4 different levels. Subjects were classified as level 1 if they did not find correct main effects, and no interaction effect; as level 2 if they did find correct main effects but no interaction effect; as level 3 if they found correct main effects and the correct interaction effect, but also one or more incorrect effects; finally, as level 4 if they found correct main effects and the correct interaction effect, and no other effects. The category a subject is classified in can be used as a measure for the level of discovery skills, with level 1 being the lowest, and level 4 the highest level of discovery skills. While answering the test, subjects were allowed to examine the experiments they had carried out and any notes they had made on paper, but they were not allowed to create any new experiments in FILE.

\section{Process measures}

All operations that subjects performed in the Optics computer simulation were automatically registered by the computer they were working on. This made it possible to analyze the activity subjects showed while they worked with the simulation.

\section{Procedure}

The experiment was divided over two sessions, about one week after another. The sessions lasted about 80 minutes. In both conditions the same procedure was followed. In the first session the pretests were administered. The tests were administered one by one in the following sequence: first the generic knowledge test, which took about 25 minutes to complete, next the domain-specific knowledge test which took about 15 minutes, and finally the discovery skills test. To log in on the computer for the discovery skills FILE task, each subject was given a login code. Subjects worked on the FILE task for about 30 minutes, after which a short paper-and-pencil test was administered. The second session was spent on working with the Optics computer simulation. Subjects were informed at the start of the session that they would receive a knowledge test afterwards. All subjects were given an instruction sheet which contained an explanation of buttons and tools in the Optics computer simulation. This sheet remained available to subjects during the session. Both conditions received similar instructions. However, subjects in the experiment condition received added instruction on the use of knowledge tips. In both conditions, subjects were given the assignment to perform experiments with Optics, and to use the tools they had at their disposal in the virtual environment of the simulation. The instruction encouraged subjects to make use of the clues that were given by the simulation, and to make notes on paper. During the session, subjects who got stuck were always referred to the assignment and the instruction sheet. No further instructions were given. All subjects started experimenting with the Optics simulation at the same time. Subjects worked with the simulation for approximately 50 minutes, after which the program was ended and the domain-specific knowledge posttest was 
handed out. The posttest was administered the same way as the pretest, and took subjects approximately 15 minutes to complete.

\section{Results}

Two types of results are relevant for the present experiment: performance on the three pretests and the posttest, and the process data. Analysis showed no difference between the two school classes that participated in the experiment, so only results for the complete group are described in this section. Test results are described first, followed by process results.

\section{Test measures}

Reliability for the test for generic knowledge of mathematical relations (as measured by Cronbach's $\alpha$ ) was 0.71 . Test scores ranged from 11 to 28 (out of 32 test items), with a mean score of 21.1 (standard deviation 4.2).

Reliability for the domain-specific knowledge pretest was 0.51 , and for the posttest 0.66 . The mean pretest score was 15.3 out of 30 test items (standard deviation 3.7), mean posttest score was 14.9 (standard deviation 4.2). Test scores ranged for the pretest from 9 to 25 , and for the posttest from 4 to 21 . Overall, no difference between pretest and posttest scores was found. Figure 5 shows in a graph the test results split for the experiment and control condition.

Figure 5 about here

As can be seen from the graph, there is a curious result: subjects in the control condition performed relatively well on the pretest. However, for this condition performance on the posttest was lower than on the pretest. In contrast, in the experiment condition mean performance increased. A one-tailed t-test of independent samples shows that the difference between improvement from pretest to posttest in the two conditions is statistically significant; $\left(\mathrm{F}_{1,24}=3.21 ; \mathrm{p}<.05\right)$.

Dependent on the results of the test for discovery skills, subjects were classified into one of four different levels. Of the 32 subjects, 8 were classified on level 1 (the lowest level), 17 as level 2, 3 as level 3, and 4 as level 4 (the highest level). One implication of this result is that 78 Percent of the subject group was not able to discover an interaction effect in data from the FILE task.

In Table 1, correlations between the four knowledge measures are shown (generic knowledge, domain-specfic prior and posttest knowledge, and discovery skills). As can be seen, all between-test correlations are close to zero. In addition, for both conditions in the experiment correlations between pretest and posttest domain-specific knowledge test scores were computed. For the control condition, the result shows a correlation of 0.52 , a moderately 
high pretest-posttest correlation. For the experiment condition, the correlation is -0.47 , moderately negative. These results replicate earlier findings (Hulshof \& De Jong, 2004).

\section{Process measures}

In the session in which subjects worked with the Optics simulation, 27 subjects participated, 15 in the control condition and 12 in the experiment condition. In the experiment condition, one subject did not access any tips at all. Because the reason for this is unclear (which makes it difficult to assign the results to any of the two conditions), it was decided to discard the process results for this subject from the analysis. All operations subjects performed in the simulation were registered and available for further analysis. For the present study, two results are especially relevant: differences between the experimental conditions with regard to interaction with Optics, and the use of knowledge tips by subjects in the experiment condition.

Interaction with Optics. The analysis of interaction with Optics focused on a subset of all possible operations: the 'basic operations'. Basic operations are those that are central to the process of experimentation. Together, the basic operations constitute more than three quarters of all operations that subjects performed in the simulation. Three different operations were examined: addition of objects to the working area in the simulation, removal of objects from the working area, and movement of objects in the working area. On average, subjects in the control condition performed $70.3(\mathrm{SD}=43.4)$, and in the experiment condition 60.1 basic operations $(\mathrm{SD}=37.5)$. This difference is not statistically significant. In Figure 6, a comparison between the experimental conditions is shown for each of the basic operations.

Figure 6 about here

As can be seen from the figure, there are small but consistent differences between subjects in the two conditions for all three basic operations. Subjects in the control condition performed more basic operations than subjects in the experiment condition. This finding can be explained by the availability of knowledge tips in the experiment condition: the fact that accessing and reading knowledge tips takes time influenced subjects' level of activity.

Because most subjects in both conditions scored close to the mean on the different knowledge tests, a comparison of subjects with low or high knowledge or skill could only be carried out on a small number of cases. Only subjects who scored more than one standard deviation below or above the mean were included in the analysis. For generic knowledge, this meant that two groups were formed of subjects who scored below $17(n=4)$ or above $25(n=4)$. The results are shown in Figure 7.

Figure 7 about here 
As can be seen in the figure, subjects with high generic knowledge were more active in working with the Optics simulation than subjects with poor generic knowledge. For domainspecific knowledge, the groups were formed of subjects who scored below $12(n=6)$ or above $19(n=5)$. Results are shown in Figure 8.

Figure 8 about here

The results are similar to the findings for generic knowledge: subjects with more knowledge about optics showed more activity for all basic operations. For discovery skills, the groups were formed of subjects who were classified at the lowest level $(n=6)$ or at the highest level $(n=3)$. Results are shown in Figure 9.

Figure 9 about here

The results differ from the other comparisons. Both groups performed a similar amount of Add and Delete operations, but subjects with high discovery skills performed much more Move operations than subjects with low discovery skills.

Use of tips. In the experiment condition, subjects could access knowledge tips if they wished to do so. The minimum number of tips that was viewed was 1, the maximum all 9 tips. The average number of accessed tips was 6 (standard deviation 2.6). Table 2 shows correlations between performance on the different test measures and the number of tips accessed by subjects.

Table 2 about here

As can be seen from the table, there is a statistically significant correlation between domainspecific prior knowledge and the number of tips accessed in the simulation: more competent subjects accessed more knowledge tips than others. Although not statistically significant, it can be observed that there is also a positive relation between the level of generic knowledge and the number of accessed tips. 


\section{Discussion}

This study examined the effect of facilitating access to domain-specific and generic information during scientific discovery learning with a computer simulation called 'Optics'. The study compared the interaction behavior with Optics and knowledge acquisition of two randomly created groups of students: one group who worked with Optics without support (the control condition), and one group who were supported while they worked with Optics (the experiment condition). The type of support used in the experiment condition was the use of a small set of 'knowledge tips', hints containing general information on the topic of the simulation: geometrical optics. A distinguishing feature of these tips is that they were not used to guide students while they explored and experimented with the discovery learning environment. Instead, students could decide for themselves whether or not they wanted to make use of the available tips. Information was available to students on a 'just in time'-base, which means that it could be voluntarily accessed during learning. As a result of the relatively small difference between the conditions that were used in the experiment, the interaction behavior with Optics was similar for subjects in both the control and the experiment condition. Subjects in the control condition were only a little more active than subjects in the experiment condition. The differences can be explained by the time taken by subjects in the experiment condition to access and read the knowledge tips. Differences between the two conditions become more apparent when the results from the domain-specific knowledge tests are compared. Subjects in the experiment condition showed a significant learning gain from pretest to posttest, in contrast to subjects in the control condition who even showed a small decline in knowledge. This finding suggests that subjects in the experiment condition benefited from the availability of tips. It should be pointed out that the questions that were used to test for domain knowledge did not ask for information that was contained within the knowledge tips. Who benefits most? In the control condition, a positive correlation was found between performance on the pretest and posttest. In the experiment condition, a negative correlation was found. The positive correlation in the control condition indicates that the effect of working with Optics was similar for all subjects in this condition. Further analysis shows that the negative correlation in the experiment condition can be explained by the performance of a number of subjects who did poorly on the pretest but showed a large increase from pretest to posttest. It can be concluded that the subjects who benefited most from the availability of tips were those subjects who showed a low understanding of the domain prior to the experiment. It is interesting to note that the positive correlation between the number of tips that subjects accessed during the experiment and domain-specific prior knowledge indicates that subjects with low prior knowledge accessed fewer knowledge tips than subjects with higher prior knowledge. This means that in some cases, accessing only a few knowledge tips resulted in a large increase in performance on the posttest.

The other tests that were administered in the experiment show mixed results. Most subjects performed well on generic knowledge measures, which means that they had no trouble in understanding the type of qualitative and quantitave relations that occur between variables in the Optics simulation. The relatively high level of generic knowledge may have facilitated understanding of the knowledge tips in the experiment condition. In contrast to the good results on the generic knowledge test, on the test for discovery skills most subjects showed a relatively poor performance. Classification of subjects was based on the number and type of rules they were able to discover after working with the FILE task. This showed that $78 \%$ of 
the subjects did not mention the presence of an interaction effect. Given the fact that the FILE task was relatively simple because its experiment space is relatively small, the learning gain in the experiment condition after working with the complex Optics simulation is almost a surprising outcome. Optics should probably not be viewed as just a complex version of the FILE discovery task, since FILE deals with an artificial topic and Optics deals with geometrical optics, a real-world topic. This may explain the absence of a relation between performance on the discovery skills test and knowledge gain from working with Optics.

What this study shows is that computer simulations can be effective tools for learning, even when the process of discovery learning is applied to the complex domain of geometrical optics. The unobtrusive method of just-in-time support helps to improve the effectiveness of discovery learning. 


\section{Acknowledgements}

Development of the Optics simulation took place in the context of the Inductive Learning project, which was supported by a grant from the Dutch National Science Foundation (NWO 575-22.002). Optics was programmed by Jan Wielemaker (Department of Social Science Informatics, University of Amsterdam, the Netherlands) to whom the authors would like to express their gratitude. The authors would also like to thank Pascal Wilhelm, Frans Prins, Hedderik van Rijn, Marcel Veenman, Wouter van Joolingen, Maarten van Someren, Bert Bredeweg and Bob Wielinga for their useful comments. 


\section{References}

Angrist, J., \& Lavy, V. (2002). New evidence on classroom computers and pupil learning. The Economic Journal, 112, 735-765.

Berry, D. C., \& Broadbent, D. E. (1987). Explanation and verbalization in a computerassisted search task. The Quarterly Journal of Experimental Psychology, 39A, 585609.

Bruner, J. S. (1961). The act of discovery. Harvard Educational Review, 31, 21-32.

Hasselerharm, E., \& Leemkuil, H. (1990). The relation between instructional control strategies and performance and attitudes in computer-based in-struction. In J. M. Pieters, P. R. J. Simons, \& L. De Leeuw (Eds.), Research on Computer-based Instruction. Amsterdam: Swets \& Zeitlinger.

De Jong, T. (1991). Learning and instruction with computer simulations. Education \& Computing, 6, 217-229.

De Jong, T., \& Van Joolingen, W. R. (1998). Scientific discovery learning with computer simulations of conceptual domains. Review of Educational Research, 68, 179-201.

De Jong, T., Beishuizen, J., Hulshof, C., Prins, F., van Rijn, H., van Someren, M., Veenman, M., \& Wilhelm, P. (in press). Determinants of discovery learning in a complex simulation learning environment. in: P. Gardenfors and P. Johansson (eds): Cognition, Education and Technology, Lawrence Erlbaum.

Van Joolingen, W. R. (1993). Understanding and Facilitating Discovery Learning in Computer-based Simulation Environments. PhD Thesis, University of Eindhoven, The Netherlands.

Van Joolingen, W. R., \& De Jong (1997). An extended dual search space model of scientific discovery learning. Instructional Science, 25, 307-346.

Hulshof, C. D. (2001). Discovery of ideas and ideas about discovery: The influence of prior knowledge on scientific discovery learning in computer-based simulations. $\mathrm{PhD}$ Thesis, University of Twente, The Netherlands.

Hulshof, C. D., Wilhelm, P., Beishuizen, J. J., \& Van Rijn, H. (2004). FILE: A Tool for the Study of Inquiry Learning. Computers in Human Behavior.

Hulshof, C. D., \& De Jong, T. (2004). Prior knowledge and scientific discovery learning. Unpublished manuscript.

Klahr, D. (2000). Exploring Science: The Cognition and Development of Discovery Processes. Cambridge, London: MIT Press.

Klahr, D., \& Dunbar, K. (1988). Dual space search during scientific reasoning. Cognitive Science, 12, 1-48.

Klahr, D., \& Nigam, M. (2004). The equivalence of learning paths in early science instruction: effects of direct instruction and discovery learning. To appear in Psychological Science.

Leutner, D. (1993). Guided discovery learning with computer-based simulation games: effects of adaptive and non-adaptive instructional support. Learning and Instruction, 3, 113-132.

Newell, A., \& Simon, H. A. (1972). Human Problem Solving. Englewood Cliffs, NJ: Prentice-Hall.

Njoo, M. K. H., \& De Jong, T. (1993). Exploratory learning with a computer simulation for control theory: Learning processes and instructional support. Journal of Research in Science Teaching, 30, 821-844. 
Pieters, J. M., \& Van der Meij, H. (1994). When support hampers: Constructivism and minimalism in supporting knowledge acquisition. Paper presented at the AERA Annual Meeting, New Orleans, April 4-9.

Steinberg, R. N. (2000). Computers in teaching science: to simulate or not to simulate? American Journal of Physics, 68, S37-S41.

Shute, V. J. (1993). A comparison of learning environments: All that glitters... In S. P. Lavoie, \& S. J. Derry (Eds.), Computers as Cognitive Tools (pp. 279-299). Hillsdale, New Jersey: Erlbaum.

Stoll, C. (1999). High Tech Heretic. Why Computers Don't Belong in the Classroom and Other Reflections by a Computer Contrarian. New York: Doubleday.

Tschirgi, J. S. (1980). Sensible reasoning: A hypothesis about hypotheses. Child Development, 51, 1-10.

Veermans, K. H. (2001). Intelligent support for discovery learning: Using opportunistic learner modeling and heuristics to support simulation based discovery learning. $\mathrm{PhD}$ Thesis, University of Twente, The Netherlands.

Wilhelm, P., Beishuizen, J. J., \& Van Rijn, H. (2004). Studying inquiry learning with FILE. Computers in Human Behavior. 


\section{Tables and Figures}

Table 1. Correlations between prior knowledge test measures

\begin{tabular}{lrrr} 
Knowledge measure & Domain posttest & Generic & Discovery skills \\
\hline Domain pretest & .13 & .27 & .13 \\
Domain posttest & & .04 & .05 \\
Generic & & & .25
\end{tabular}


Table 2. Correlations between knowledge measures and the number of accessed tips Knowledge measure Accessed tips

Generic knowledge .39

Discovery skills

$-.24$

Domain-specific prior knowledge

$.66^{*}$

Domain-specific post knowledge

$-.36$ 


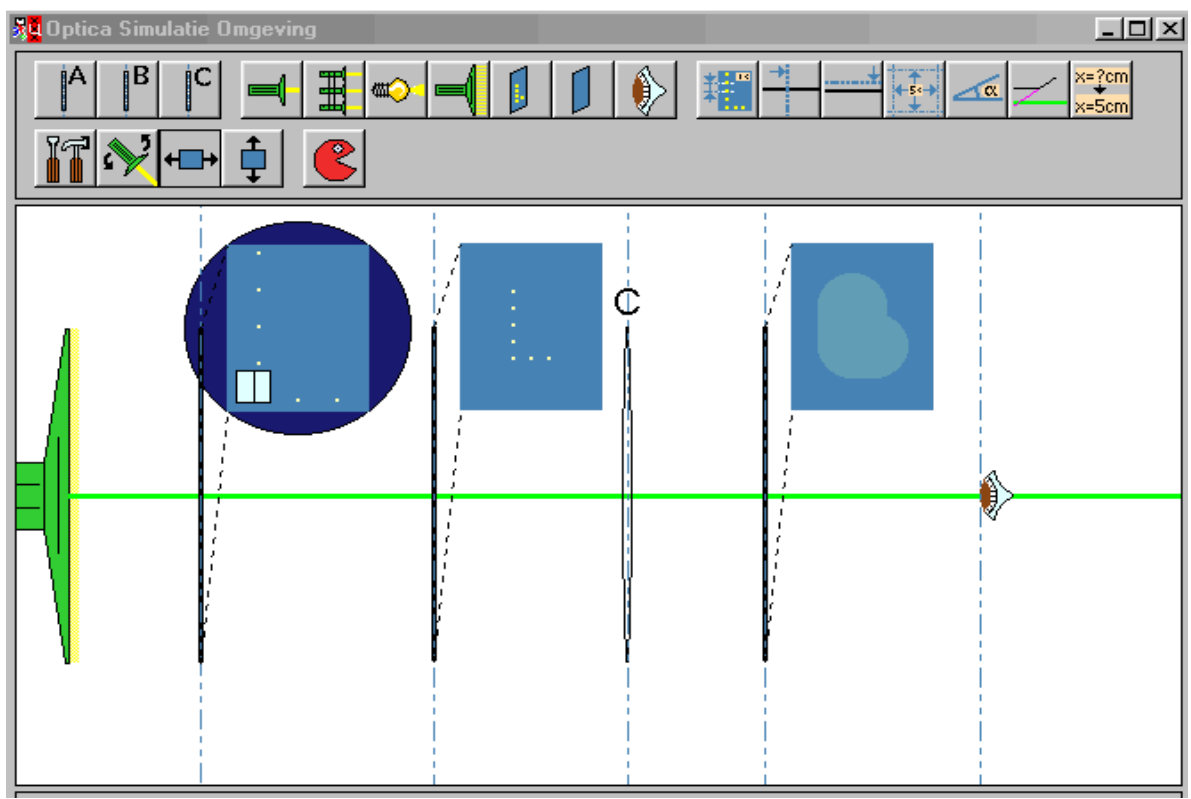

Figure 1. Example interface of the Optics simulation environment. Explanation given in text 


\section{Tip Content}

1. a) A thin lens is a weak lens, a thick lens is a strong lens.

b) Advice: Compare different lenses with each other and observe differences.

c) Appropriate object to use: lamp with one light beam.

d) Expected outcome: Light beams are refracted more through a thick lens than through a thin lens.

6. a) When an object is standing within the focal distance of a lens, the projected image becomes virtual. This means that the image will lie at the left of the lens

b) Advice: The 'eye' was developed for this program to show you the position and shape of the virtual image. Put the eye somewhere to the right of the lens. When the object gets near to the lens, you will see the virtual image appear.

c) Appropriate object to use: surface with L-shaped holes, screen, lamp with three divergent light beams, distance measures, eye.

Figure 2. Two example tips (tip 1 and 6), used in the experiment condition 
The table shows for some values the relation between variables $\mathrm{A}$ and $\mathrm{B}$. Which description on the right best summarizes this relation?

\begin{tabular}{|l|lll|}
\hline A & B & Answer \\
\hline 10 & 4 & $\square$ & The more A increases, the slower B increases \\
20 & 8 & $\square$ & When A is zero, B is also zero \\
30 & 16 & $\square$ & The more A decreases, the faster B decreases \\
60 & 64 & $\square$ & The more A increases, the faster B increases \\
100 & 1024 & & \\
\hline
\end{tabular}

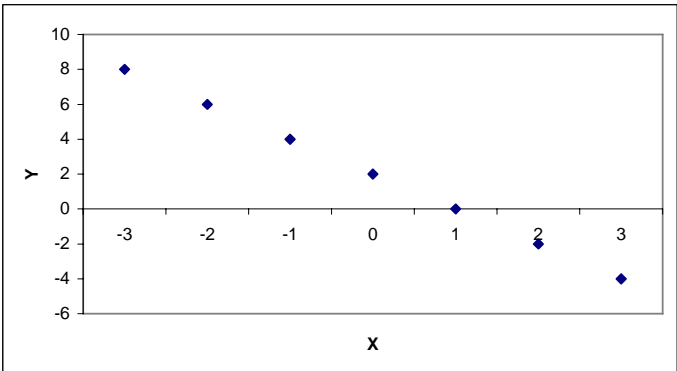

What type of function describes a line that goes through all the points in the graph on the left?

- A quadratic function

- A function with an asymptote

口 A monotonic decreasing function

a A logarithmic function

Figure 3. Example items from the generic knowledge test (slightly modified for legibility) 


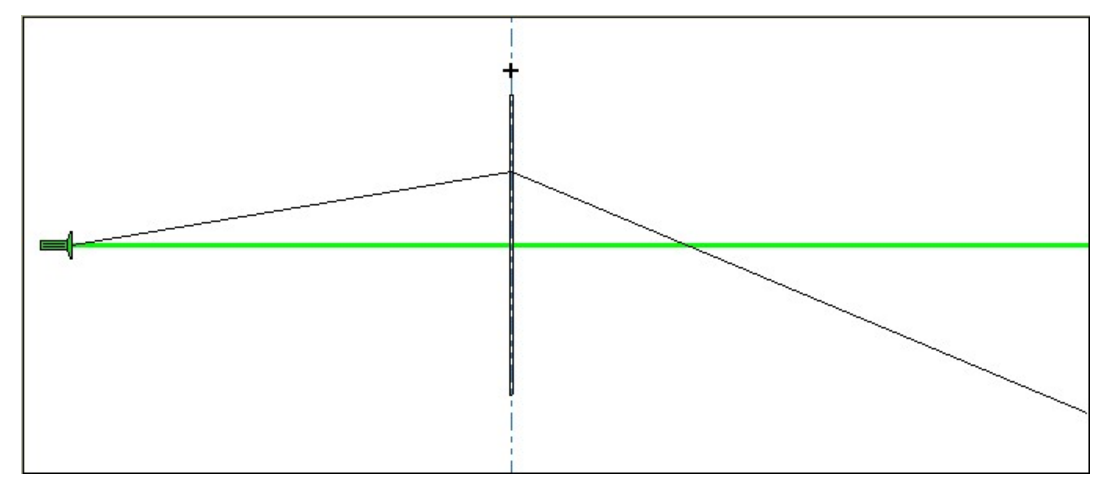

Study the Picture. If the lens is moved a little to the left, where will the light beam cross the base line?

a Closer to the lens

a At the same distance from the lens

a Further away from the lens

If, in the same picture, the light beam is aimed a little up, where will it cross the base line?

a Closer to the lens

a At the same distance from the lens

a Further away from the lens

Figure 4. Example items from the domain-specific knowledge test 


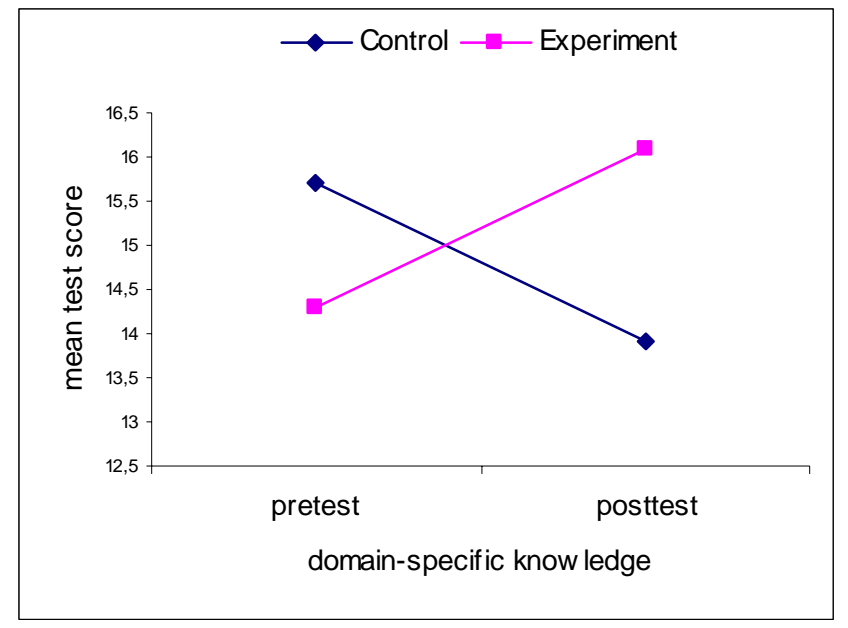

Figure 5. Comparison of the control and experiment condition for domain-specific test scores 


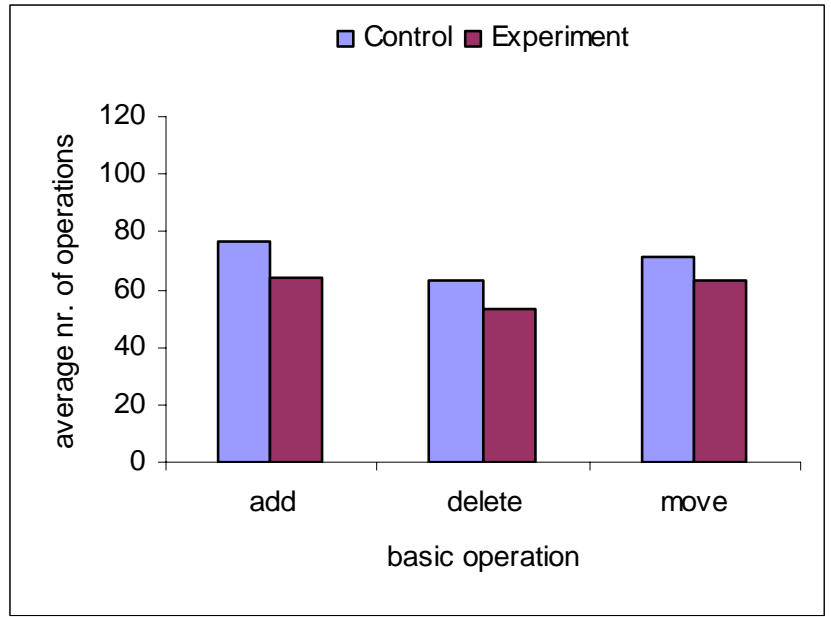

Figure 6. Comparison of control and experiment conditions for basic operations in Optics 


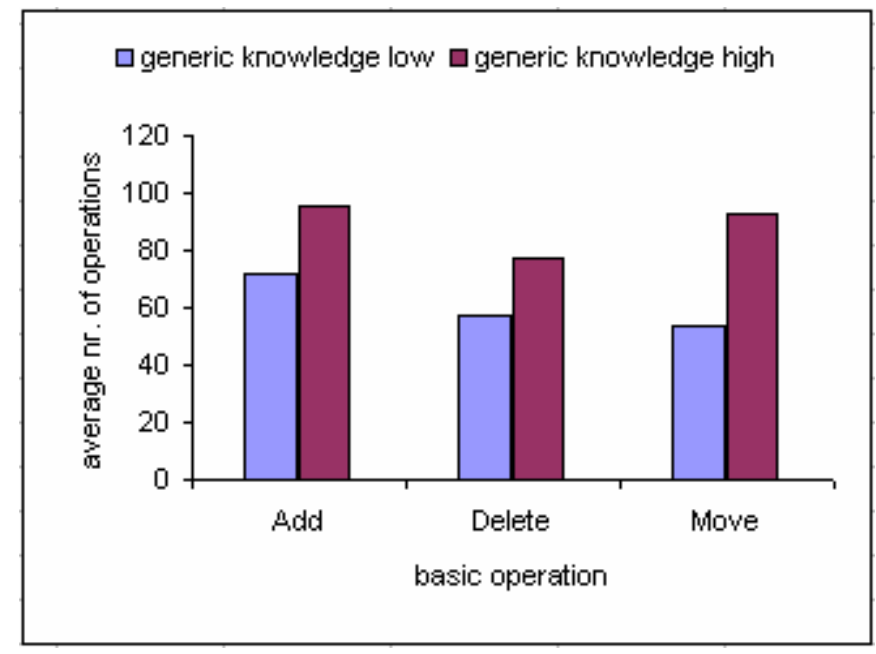

Figure 7. Comparison on basic operations for low and high generic knowledge 


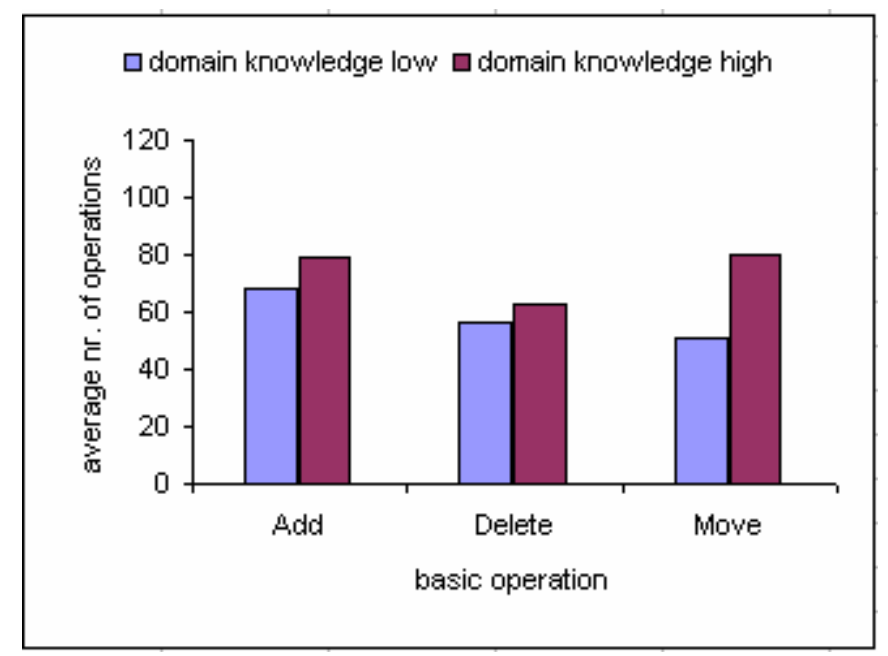

Figure 8. Comparison on basic operations for low and high domain-specific knowledge 


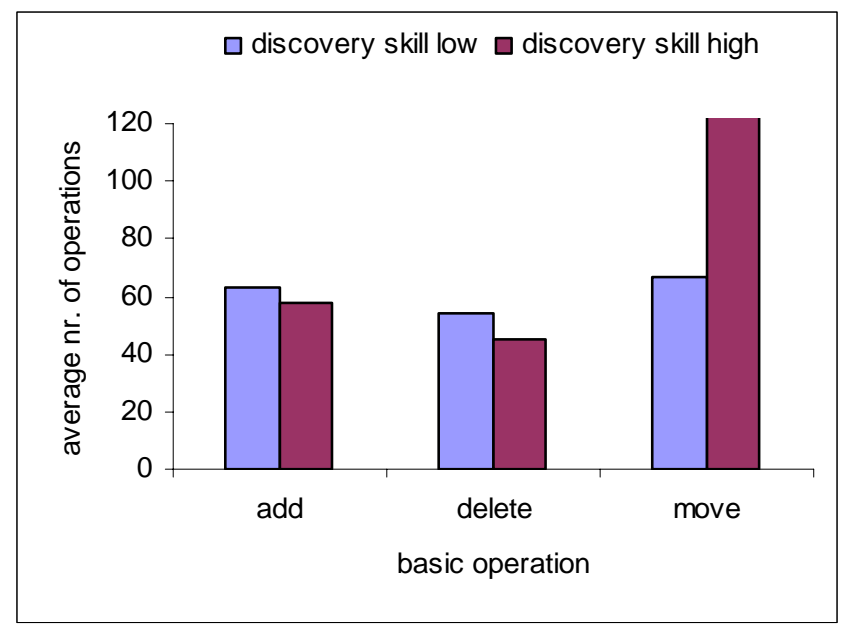

Figure 9. Comparison on basic operations for poor and high discovery skills 